\title{
Biogeophysical and biogeochemical impacts of land-use change simulated by MIROC-ES2L
}

\author{
Akihiko Ito ${ }^{1,2^{*}}$ and Tomohiro Hajima ${ }^{2}$
}

\begin{abstract}
Land-use change is one of the focal processes in Earth system models because it has strong impacts on terrestrial biogeophysical and biogeochemical conditions. However, modeling land-use impacts is still challenging because of model complexity and uncertainty. This study examined the results of simulations of land-use change impacts by the Model for Interdisciplinary Research on Climate, Earth System version 2 for long-term simulations (MIROC-ES2L) conducted under the Land-Use Model Intercomparison Project protocol. In a historical experiment, the model reproduced biogeophysical impacts such as decreasing trends in land-surface net radiation and evapotranspiration by about 1970. Among biogeochemical impacts, the model captured the global decrease of vegetation and soil carbon stocks caused by extensive deforestation. By releasing ecosystem carbon stock to the atmosphere, land-use change shortened the mean residence time of terrestrial carbon and accelerated its turnover rate, especially in low latitudes. Future projections based on Shared Socioeconomic Pathways indicated substantial alteration of land conditions caused primarily by climatic change and secondarily by land-use change. Sensitivity experiments conducted by exchanging land-use data between different future projection baseline experiments showed that, at the global scale, the anticipated extent of land-use conversion would likely play a modest role in the future terrestrial radiation, water, and carbon budgets. Regional investigations revealed that future land use would exert a considerable influence on runoff and vegetation carbon stock. Further model refinement is required to improve its capability to analyze its complicated terrestrial linkages or nexus (e.g., food, bioenergy, and carbon sequestration) to climate-change impacts.
\end{abstract}

Keywords: Carbon cycle, Earth system model, Deforestation, Hydrology, Radiation budget, Terrestrial ecosystem

\section{Introduction}

Land-use change (e.g., expansion of cropland at the cost of primary forest) associated with the human population and economic growth is a critical driver of global change (Houghton 1994; Foley et al. 2005). In a broad sense, land-use change encompasses various human activities such as harvesting trees for fuel wood, shifting cultivation, pasturing of livestock, and selective logging. Extensive deforestation of tropical rainforests (e.g., in the

\footnotetext{
* Correspondence: itoh@nies.go.jp

${ }^{1}$ National Institute for Environmental Studies, 16-2 Onogawa, Tsukuba 305-8506, Japan

${ }^{2}$ Japan Agency for Marine-Earth Science and Technology, 3173-25

Showa-machi, Kanazawa-ku, Yokohama 236-0001, Japan
}

Amazon basin and Southeast Asia) has garnered particular attention (Woodwell et al. 1983; Malhi et al. 2008; DeFries and Rosenzweig 2010). As a result of long-term land use, most natural vegetation has been influenced by human activities, with the exception of limited reserved land areas (Pongratz et al. 2009; Kaplan et al. 2010). Drastic land cover changes have an immediate impact on surface biophysical characteristics such as albedo and roughness (Henderson-Sellers et al. 1993), which greatly affect the net radiative and hydrological budgets at the land surface and subsequent propagation of these effects leads to impacts on local to global atmospheric dynamics (Sud et al. 1996; Takata et al. 2009).

\section{Springer Open}

(0) The Author(s). 2020 Open Access This article is licensed under a Creative Commons Attribution 4.0 International License, which permits use, sharing, adaptation, distribution and reproduction in any medium or format, as long as you give appropriate credit to the original author(s) and the source, provide a link to the Creative Commons licence, and indicate if changes were made. The images or other third party material in this article are included in the article's Creative Commons licence, unless indicated otherwise in a credit line to the material. If material is not included in the article's Creative Commons licence and your intended use is not permitted by statutory regulation or exceeds the permitted use, you will need to obtain permission directly from the copyright holder. To view a copy of this licence, visit http://creativecommons.org/licenses/by/4.0/. 
Land-use change and associated biomass burning is the second largest anthropogenic source of atmospheric carbon dioxide $\left(\mathrm{CO}_{2}\right)$ emissions; during 2001-2015, it was responsible for $1.37 \pm 0.18 \mathrm{Pg} \mathrm{C}$ year ${ }^{-1}$ of $\mathrm{CO}_{2}$ emissions to the atmosphere (Friedlingstein et al. 2019), mainly from deforestation in tropical forests. In contrast, the combination of afforestation and moderate forest management is a cost-effective way to sequester carbon from the atmosphere for the purpose of climate mitigation (Smith et al. 2016). Remarkably, the regrowth of vegetation after deforestation and cropland abandonment results in net carbon sequestration at decadal to centennial time scales.

Drivers of land-use change and its ecological, meteorological, and social impacts have been investigated with the aim of improving land management practices. Recent developments in satellite remote sensing have enabled the continuous detection of deforestation throughout the tropics (DeFries et al. 2002; Hansen et al. 2013). For example, Saatchi et al. (2011) have used lidar remote sensing data to quantify the aboveground biomass of tropical forests and the carbon emissions associated with deforestation. Field studies have also been conducted to clarify the impacts of land-use changes on local biodiversity and biogeochemical cycles (e.g., Newbold et al. 2016; Marques et al. 2019). Nevertheless, our understanding of land-use changes and their impacts is severely limited, especially at decadal or longer time scales, and large uncertainties therefore remain in present assessments of the impacts of land-use change. For example, estimations of historical carbon emissions caused by land-use change differ widely among studies (Ramankutty et al. 2007; Arneth et al. 2017). This uncertainty is attributable to both the quality of land-use data and to the methodology of estimating emissions. Following a systematic assessment, Pongratz et al. (2014) concluded that ambiguities in the assumptions, definitions, and methods used in land-use emissions studies are among the critical sources of uncertainty in assessments of the impacts of land-use changes.

Appropriate implementation of land-use change processes is critically important in Earth system models (ESMs), which are being increasingly used for future projections of global environmental conditions. Early climate models considered the impacts of land-use change simply by altering surface roughness, albedo, and stomatal conductance (e.g., Henderson-Sellers et al. 1993), changes which led to immediate biogeophysical responses in the radiation and water budgets considered at hourly to monthly time scales. Like ESMs, modern climate models include biogeochemical schemes in which land-use changes affect the global carbon cycle by altering vegetation structure, productivity, and carbon stocks. However, because the processes associated with land-use change are complicated and occur heterogeneously over the land area, it is difficult to include all such processes in ESMs (Hibbard et al. 2010).

To cope with the issues of land-use simulations, the Land-Use Model Intercomparison Project (LUMIP) was initiated as a part of the Coupled Model Intercomparison Project phase 6 (CMIP6). As a part of the LUMIP, a series of experiments was proposed to evaluate the biophysical and biogeochemical impacts of land-use change associated with different drivers. This study investigated land-use impacts simulated by the Model for Interdisciplinary Research on Climate, Earth System version 2 for Long-term simulations (MIROC-ES2L) (Hajima et al. 2020), which has been used for climate projections expected to contribute to the next assessment report of the Intergovernmental Panel on Climate Change. We first briefly describe the land-use scheme in the MIROC-ES2L, and then, we present preliminary results of simulations of land-use impacts conducted under the LUMIP protocol.

\section{Methods}

\subsection{MIROC-ES2L}

MIROC is a global climate model developed mainly by the University of Tokyo and the Japan Agency for Marine-Earth Science and Technology. Hajima et al. (2020) developed MIROC-ES2L by incorporating biogeochemical processes into the well-tested MIROC general circulation model for atmospheric and oceanic physical processes (Tatebe et al. 2019). The horizontal resolution of the atmospheric component of MIROCES2L is approximately $2.8^{\circ}$ for latitude and longitude (T42 spectral truncation), and the vertical resolution is 40 layers up to $3 \mathrm{hPa}$. Land-surface physics is simulated by the Minimal Advanced Treatment of Surface Interaction and Runoff (MATSIRO) scheme (Takata et al. 2003), which simulates the exchanges of momentum, heat energy, and water between the atmosphere and land surface. The scheme uses hydrological relationships to simulate canopy transpiration, evaporation of canopy-intercepted water, soil evaporation, runoff discharge, and soil water content, and it is coupled with a river routine that enables it to simulate freshwater transport from the land to the ocean. The version used in this study takes into account sub-grid snow distributions in a more physical and realistic manner than the original model (Nitta et al. 2014). The MATSIRO scheme considers the vegetation canopy in an explicit manner; it takes into account plant physiological (i.e., stomatal) regulation of $\mathrm{CO}_{2}$ and vapor exchange and includes six soil layers.

The biogeochemical carbon cycle of terrestrial ecosystems was simulated by the Vegetation Integrative SImulator for Trace gases adapted for ESM (VISIT-e; Ito 2019). See Ito and Oikawa (2002) and Ito and Inatomi (2012) for details of the carbon cycle in VISIT-e. The simulation by this scheme of the atmosphere-land $\mathrm{CO}_{2}$ 
exchange and terrestrial carbon stocks allowed us to include carbon-cycle feedbacks in MIROC-ES2L. In this scheme, land cover in each grid is represented by five tiles (primary land, secondary land, cropland, pasture, and urban areas), and fluxes are calculated separately for each tile (Fig. 1a). The grid-average flux and carbon stock are obtained as the fraction-weighted means of the corresponding fluxes and carbon stocks of the five tiles. In each tile, vegetation biomass is composed of three organs (leaf, stem, and root), and soil organic carbon is composed of two pools (litter and mineral soil). Carbon stock and vegetation coverage in each grid, as well as responses to environmental changes such as atmospheric $\mathrm{CO}_{2}$ increases and temperature rises, are therefore simulated dynamically at each time step. Land-use change is represented by the gross transitions among the five land-cover tiles; as a result, both vegetation loss by deforestation and regrowth by cropland abandonment and afforestation can be included (Fig. 1b). When deforestation (transition from primary or secondary forest to cropland or pasture) occurs, carbon in the vegetation biomass is exported out of the grid or transferred to the litter pool at a certain rate. The exported biomass represents the wood harvest, which is separated into three pools with different residence times (1 to 100 years) before its consumption releases carbon to the atmosphere as $\mathrm{CO}_{2}$. Abandoned croplands and pastures are transferred to secondary land, which absorbs $\mathrm{CO}_{2}$ from the atmosphere as the vegetation regrows.

The land-surface biogeophysical scheme, MATSIRO, considers sub-grid heterogeneity and land-use conversion, but in a simplified manner. The scheme aggregates the five VISIT-e tiles of each grid into two (cropland and non-cropland). The cropland fraction has its own parameters, such as albedo and leaf conductance; this, a land-use change from non-cropland to cropland affects both the radiation and water budgets at the land surface. Importantly, VISIT-e provides leaf area index (LAI) data to MATSIRO, and MATSIRO provides soil moisture data to VISIT-e. Accordingly, the two schemes, which use the same land-use data, react interactively to landuse change. Although the standalone VISIT-e model is calibrated (i.e., parameters are adjusted) with observational data, the coupled model with interactive linkage between models requires further calibrations. For example, vegetation productivity, biomass, and soil carbon

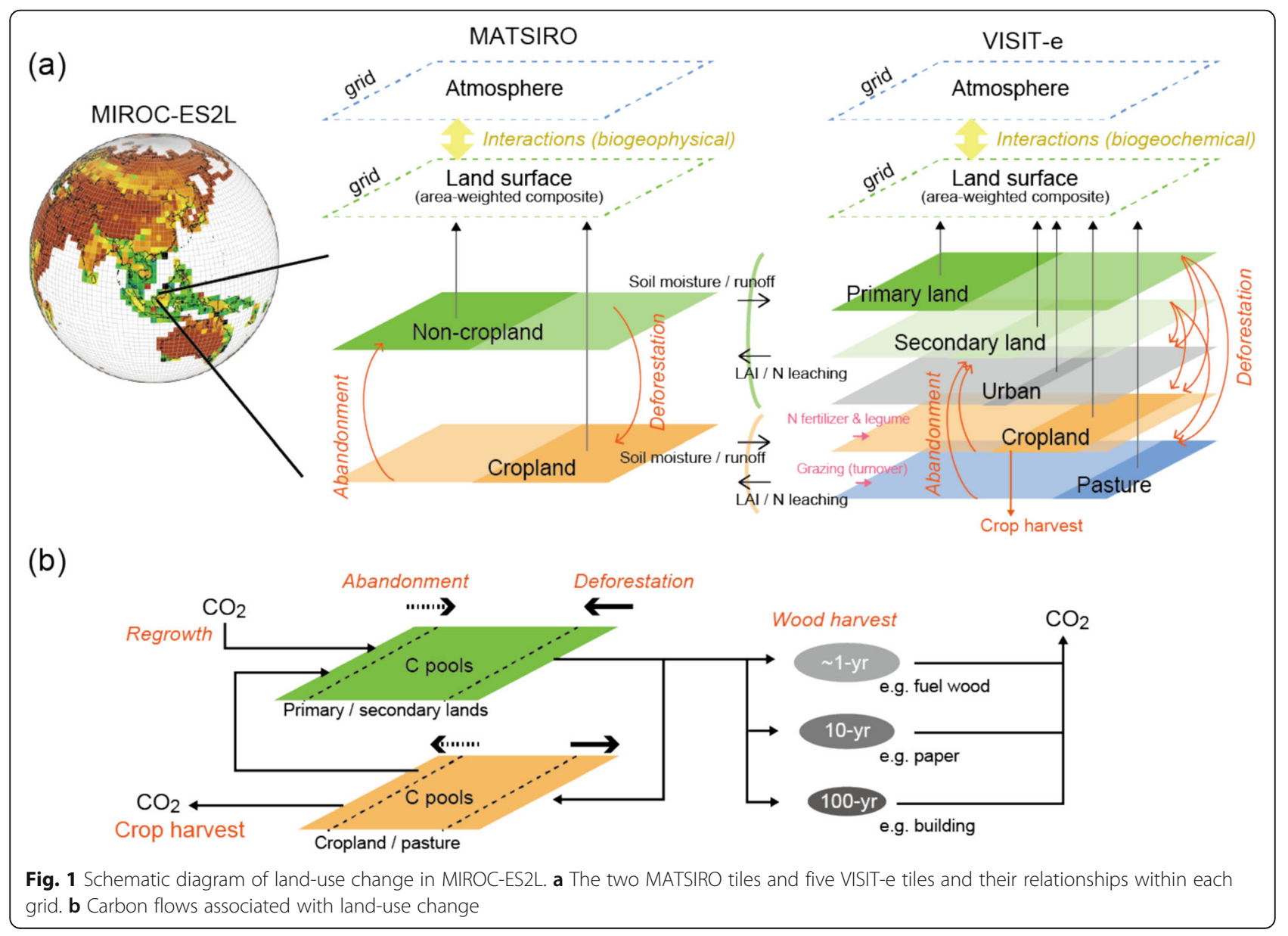


stocks are calibrated mainly by manually changing the values of photosynthetic capacity and carbon turnover parameters.

Off-line simulation results of the VISIT-e scheme have been validated by comparing them with various observational data from point scale (Ichii et al. 2013, comparison with flux-tower measurement data) to global scale (Ito et al. 2017, comparison with satellite-observed productivity), and the terrestrial carbon cycle scheme has been used to make land-use impact assessments. For example, Adachi et al. (2011) have applied VISIT (offline version) to the simulation of temporal changes in the carbon stock of a tropical rainforest in Malaysia associated with conversion to oil-palm plantations, and Hirata et al. (2014) have used a similar model in a simulation of the carbon balance of a cool-temperate, deciduous, needle-leaved forest in Japan that included land-use conversion and thinning effects. In addition, Kato et al. (2013) have used the scheme to evaluate carbon emissions associated with land-use change at a global scale. Ito (2019) used global VISIT simulations to assess the impacts of minor carbon flows, including emissions due to landuse changes, on the global carbon budget. The simulated emissions associated with land-use changes peaked at 1.2-1.4 Pg C year ${ }^{-1}$ around the 1950s and then gradually decreased. This result is comparable to estimates obtained by the book-keeping method (Houghton 2003) and to other model estimates (Fig. S1); for example, models using contemporary data have estimated emissions of $1.5 \pm 0.7$ Pg C year ${ }^{-1}$ during 2009-2018 (Friedlingstein et al. 2019). The results obtained by these studies allow us to apply MIROC-ES2L to land-use studies with confidence.

\subsection{LUMIP experiments}

LUMIP is an endorsed activity of CMIP6 with the goal of exploring various issues related to land-use change (Eyring et al. 2016; Lawrence et al. 2016). Because LUMIP was designed to address not only biophysical but also biogeochemical aspects of climate change, most ESMs participating in this task have sub-grid land fractions and carbon cycle schemes. Most LUMIP simulations use a dataset of land-use transitions (Land-Use Harmonization data version 2, LUH2; Hurtt et al. 2011) and corresponding management variables as forcing data for model simulations. The land-use transition data are developed by integrating country-based data for areas of forest, pasture, and cropland from the past to the future (harmonization). In this way, temporal expansion of the cropland area is captured in a consistent manner. The dataset comprises data for both historical (850-2014) and future (2015-2100) periods. In the present study, we considered only changes in land-use conditions; thus, technological innovations in urban and cropland areas were excluded.
Several baseline simulations using the common forcing data have been conducted as a part of CMIP6 or other tasks. Note that the experiments in this study were conducted in the "concentration-driven" mode, and modelsimulated meteorological conditions were also analyzed. LUMIP includes Tier 1 experiments with high priority and Tier 2 experiments for investigation of specific features (hereafter, experiment names are shown in italics). In this study, the historical experiment was conducted with CMIP6, in which land models were driven by climate conditions derived from coupled climate models. In contrast, the land-hist experiment was driven by observed climate conditions, so that land processes were not influenced by model-specific land-atmosphere feedbacks. The land-hist experiment was a collaborative effort with the Land Surface, Snow, and Soil moisture Model Intercomparison Project (LS3MIP; van den Hurk et al. 2016). To remove the historical impact of land-use change from the historical and land-hist experiments, idealized experiments, hist-noLu and land-noLu, were conducted in which a constant cropland distribution was used throughout each simulation. In the future projection period, two baseline experiments, ssp126 and ssp370, were conducted that used Shared Socioeconomic Pathways (SSPs) based on certain socio-economic assumptions and models as land-use scenarios (van Vuuren et al. 2017). These experiments were carried out collaboratively in conjunction with the Scenario Model Intercomparison Project (O'Neill et al. 2016). The ssp126 experiment assumed a sustainable, mitigation-oriented society and thus represents the low end of the range of possible global warming states. The ssp370 experiment assumed regional rivalry and thus represents the high-end of the range of possible global warming states. The ssp370 scenario assumes a larger extent of cropland expansion at the cost of forests and other natural lands than the ssp126 scenario. Importantly, however, the ssp126 scenario also assumes a substantial amount of land-use conversion (e.g., loss of primary land), because it assumes that large areas are devoted to biofuel cultivation. To clarify the impacts of different land-use extents, data-exchange experiments are included in the LUMIP protocol. The ssp126_ssp370Lu experiment uses mainly ssp 126 forcing data but ssp 370 land-use data. The difference between the ssp126 and ssp126_ssp370Lu shows the impacts of extensive cropland expansion. Similarly, the ssp370_ssp126Lu experiment uses mainly ssp 370 forcing data but ssp126 land-use data. In addition, an idealized deforestation experiment, deforest_glob, is included in the protocol. In that experiment, $20 \times 10^{6} \mathrm{~km}^{2}$ of forest is cleared at a constant rate during the period $1850-1899$. The $30 \%$ of grids with the highest tree-cover fraction are selected for deforestation, to represent an extreme deforestation case. After 1899, a 30-year restoration period with constant forest cover is simulated. 


\subsection{Analyses of land-use impacts}

We focused on the biophysical variables net radiation (rnet [CMIP6 variable name], $\mathrm{W} \mathrm{m}^{-2}$ at grid scale and zettajoules [ZJ] at global scale), temperature (tas, K), evapotranspiration including sublimation (evspsbl, $\mathrm{kg}$ $\mathrm{H}_{2} \mathrm{O} \mathrm{m} \mathrm{m}^{-2} \mathrm{~s}^{-1}$ at grid scale and $10^{3} \mathrm{~km}^{3}$ year $^{-1}$ at global scale), and total runoff discharge (mrro, $\mathrm{kg} \mathrm{H}_{2} \mathrm{O} \mathrm{m}{ }^{-2} \mathrm{~s}^{-1}$ at grid scale and $10^{3} \mathrm{~km}^{3}$ year ${ }^{-1}$ at global scale). We also focused on the biogeochemical variables net primary production (npp, $\mathrm{kg} \mathrm{C} \mathrm{m}^{-2} \mathrm{~s}^{-1}$ at grid scale and Pg C year $^{-1}$ at global scale), leaf area index (lai, $\mathrm{m}^{2} \mathrm{~m}^{-2}$ ), vegetation carbon stock (cVeg, $\mathrm{kg} \mathrm{C} \mathrm{m}^{-2}$ at grid scale and $\mathrm{Pg}$ $\mathrm{C}$ at global scale), and soil carbon stock (cSoil, $\mathrm{kg} \mathrm{C} \mathrm{m}^{-2}$ at grid scale and $\mathrm{Pg} \mathrm{C}$ at global scale). We compared the temporal trajectories of the global means of these focal variables and examined the spatial distributions of the differences between experiments.

Differences between the experiments indicated the impacts of land-use change, including both direct and indirect (e.g., via alteration of climatic conditions) effects. For the historical period, we analyzed the difference between historical and hist-noLu. For the future period, we analyzed the differences between ssp126 and ssp126_ssp370Lu, and between ssp370 and ssp370_22p126Lu. Regional analyses were conducted for six regions (Fig. S2): Asia $\left(20^{\circ} \mathrm{S}-80^{\circ} \mathrm{N}, 60\right.$ $\left.180^{\circ} \mathrm{E}\right)$, Oceania $\left(20-80^{\circ} \mathrm{S}, 60-180^{\circ} \mathrm{E}\right)$, Africa $\left(45^{\circ} \mathrm{S}-35^{\circ}\right.$ $\left.\mathrm{N}, 30^{\circ} \mathrm{W}-60^{\circ} \mathrm{E}\right)$, Europe $\left(35-85^{\circ} \mathrm{N}, 30^{\circ} \mathrm{W}-60^{\circ} \mathrm{E}\right)$, North America $\left(15-85^{\circ} \mathrm{N}, 30-180^{\circ} \mathrm{W}\right)$, and South America $\left(15^{\circ}\right.$ $\left.\mathrm{N}-60^{\circ} \mathrm{S}, 30-180^{\circ} \mathrm{W}\right)$.

In addition, the mean residence time and acceleration factor of the vegetation carbon stock were analyzed to clarify land-use impacts on the terrestrial carbon cycle. In accordance with the analyses of Erb et al. (2016), the mean residence time and its acceleration factor were defined as follows:

Mean residence time $(i$ th year $)=\mathrm{cVeg}_{i} / \mathrm{npp}_{i}$

Acceleration factor (ith year) $=$ mean residence time (1st year; pre - industrial) /mean residence time (ith year)

For example, an acceleration factor of 2 indicates that the mean residence time of the vegetation carbon pool has been halved.

\section{Results and discussion}

\subsection{Land-use transitions}

The historical land-use data indicated that in 1850, 95.4 $\times 10^{6} \mathrm{~km}^{2}(73.4 \%)$ of the land area was occupied by primary lands such as natural forests, and $16.7 \times 10^{6} \mathrm{~km}^{2}$ $(12.9 \%)$ was occupied by secondary lands (Fig. 2).
Croplands and pastures covered $5.8 \times 10^{6} \mathrm{~km}^{2}(4.5 \%)$ and $12.0 \times 10^{6} \mathrm{~km}^{2}$ (9.2\%), respectively (see Fig. S3 for maps). The urban extent was quite small: $0.04 \times 10^{6} \mathrm{~km}^{2}$ (0.03\%). By 2015, the extent of primary lands had decreased considerably, to $50.2 \times 10^{6} \mathrm{~km}^{2}$ (38.6\%), because of deforestation for cultivation. Cropland and pasture areas had increased to $15.9 \times 10^{6} \mathrm{~km}^{2}(12.2 \%)$ and 32.8 $\times 10^{6} \mathrm{~km}^{2}(25.2 \%)$, respectively. The extent of urban area was still small at $0.59 \times 10^{6} \mathrm{~km}^{2}(0.45 \%)$, but it had increased rapidly (1470\% of the extent in 1850).

Under the future scenarios, the area occupied by primary land continued to decrease to the end of the twentyfirst century, to $40.9(\operatorname{ssp} 126)$ or $34.7(s s p 370) \times 10^{6}$ $\mathrm{km}^{2}$ in 2100. Both scenarios showed an expansion of the cropland area, by $1.95(\operatorname{ssp} 126)$ and $5.65(s s p 370) \times 10^{6}$ $\mathrm{km}^{2}$ by 2100 . The cropland area increased in South America and central Africa in ssp126, whereas in ssp370, it increased in western Africa, South Asia, and parts of North America and South America (Fig. S3). Interestingly, the two scenarios differed with respect to the future change in pasture area: ssp126 predicted a $6.4 \times$ $10^{6} \mathrm{~km}^{2}$, but $s s p 370$ predicted a $1.6 \times 10^{6} \mathrm{~km}^{2}$ increase. Under the ssp126 scenario, managed pasture decreased greatly in Asia and moderately in other regions until 2100 . By contrast, under the $s s p 370$ scenario, pasture in Asia decreased only weakly, and there was a considerable expansion of pasture in central Africa.

The urban area approximately doubled in both scenarios by the end of the twentyfirst century.

\subsection{Biogeophysical impacts: historical}

The correspondence between the MIROC-ES2L historical simulation of climatological state of land biogeophysial conditions (Table 1) and observations was good. For example, annual net radiation (rnet) at the land surface was simulated to range from less than $-20 \mathrm{~W} \mathrm{~m}^{-2}$ on the Antarctic and Greenland ice sheets to $>160 \mathrm{~W} \mathrm{~m}^{-2}$ in tropical and subtropical forests. This rnet distribution is consistent with satellite observations (e.g., Wielicki et al. 1996). The modeled global terrestrial water budget of precipitation, evapotranspiration, and runoff compared favorably with the budget inferred from a global hydrological synthesis (Oki and Kanae 2006).

Land-use change directly affected biogeophysical conditions by reducing vegetation coverage and associated attributes. In the historical experiment, global rnet decreased gradually until the 1980 s and then increased slightly (Fig. 3a). Regionally, the decrease in rnet occurred mainly in Asia, Africa, and the low latitudes of South America (Fig. 4a). In contrast, rnet increased in middle to high latitudes, where extensive "greening" (i.e., an increase of vegetation with low albedo) occurred (Piao et al. 2020) and snow mass, which has high albedo, decreased (Pulliainen et al. 2020). 

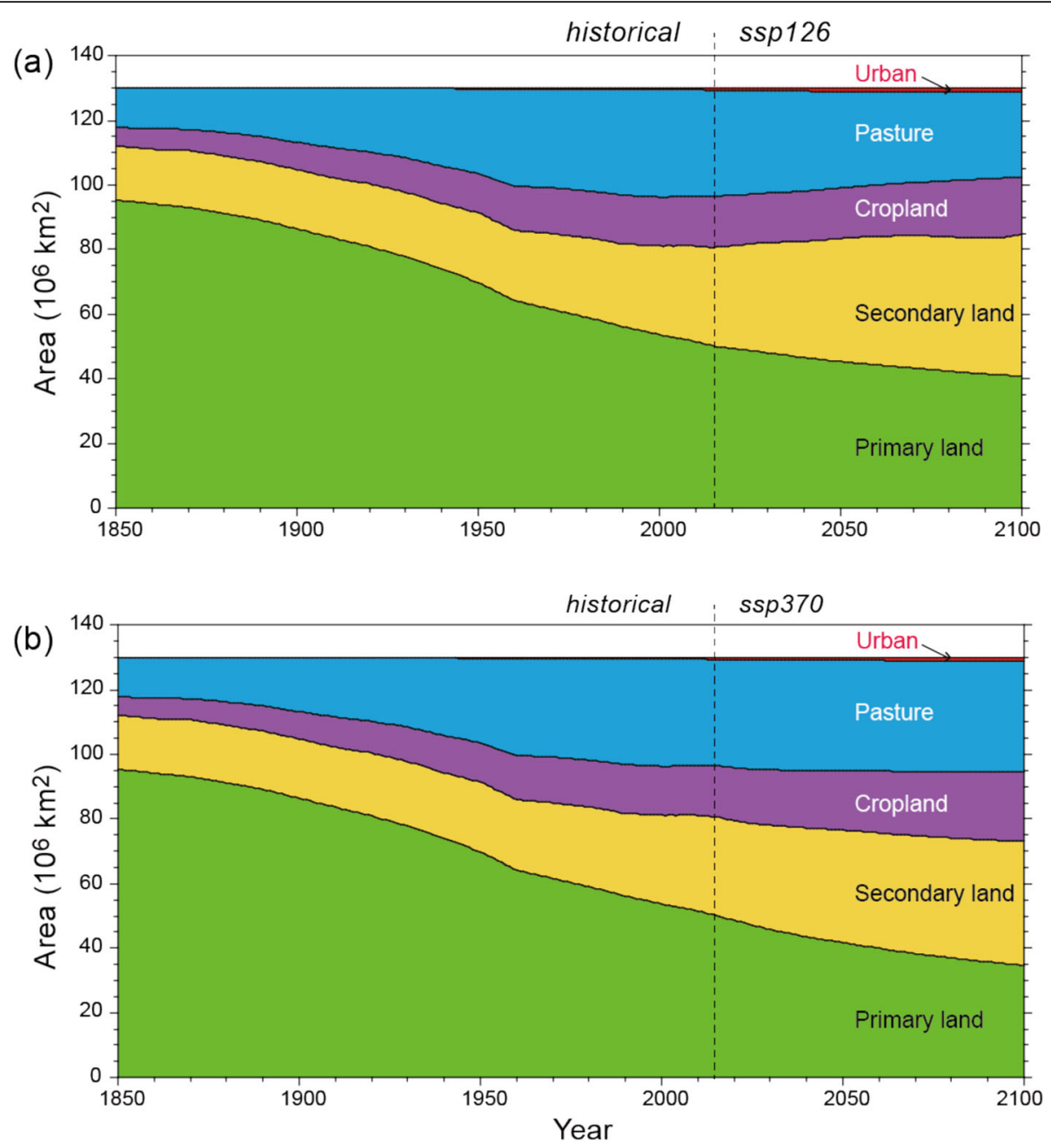

Fig. 2 Temporal changes in the global composition of land-use fractions derived from the LUH2 dataset under the historical and a ssp 126 or $\mathbf{b}$ ssp370 scenarios

Table 1 Land surface biogeophysical and biogeochemical conditions simulated by MIROC-ES2L (2005-2014 means). Regional (six regions), zonal (tropical $<25^{\circ}$ and extra-tropical $>25^{\circ}$ ), and global results are shown

\begin{tabular}{|c|c|c|c|c|c|c|}
\hline & $\begin{array}{l}\text { rnet } \\
\text { ZJ }\end{array}$ & $\begin{array}{l}\text { evspsbl } \\
10^{3} \mathrm{~km}^{3} \text { year }^{-1}\end{array}$ & $\begin{array}{l}\text { mrro } \\
10^{3} \mathrm{~km}^{3} \text { year }^{-1}\end{array}$ & $\begin{array}{l}\text { npp } \\
\mathrm{PgC} \text { year }^{-1}\end{array}$ & $\begin{array}{l}\text { cVeg } \\
\mathrm{Pg} \mathrm{C}\end{array}$ & $\begin{array}{l}\text { CSoil } \\
\text { Pg C }\end{array}$ \\
\hline Asia & 102.2 & 31.1 & 12.6 & 19.2 & 137.3 & 467.2 \\
\hline Africa & 115.3 & 25.7 & 6.3 & 13.9 & 113.7 & 116.1 \\
\hline Oceania & 23.2 & 4.9 & 0.3 & 1.8 & 16.4 & 23.6 \\
\hline Europe & 27.5 & 8.6 & 2.1 & 7.0 & 49.8 & 163.5 \\
\hline N. America & 54.4 & 15.8 & 5.9 & 12.2 & 95.7 & 298.4 \\
\hline S. America & 78.4 & 24.5 & 9.0 & 14.0 & 136.4 & 123.0 \\
\hline Tropical & 224.4 & 64.1 & 19.8 & 35.7 & 315.8 & 284.4 \\
\hline Extra-tropical & 174.2 & 47.8 & 19.7 & 32.4 & 233.7 & 907.9 \\
\hline Global & 398.6 & 111.9 & 39.5 & 68.1 & 549.4 & 1192.3 \\
\hline
\end{tabular}



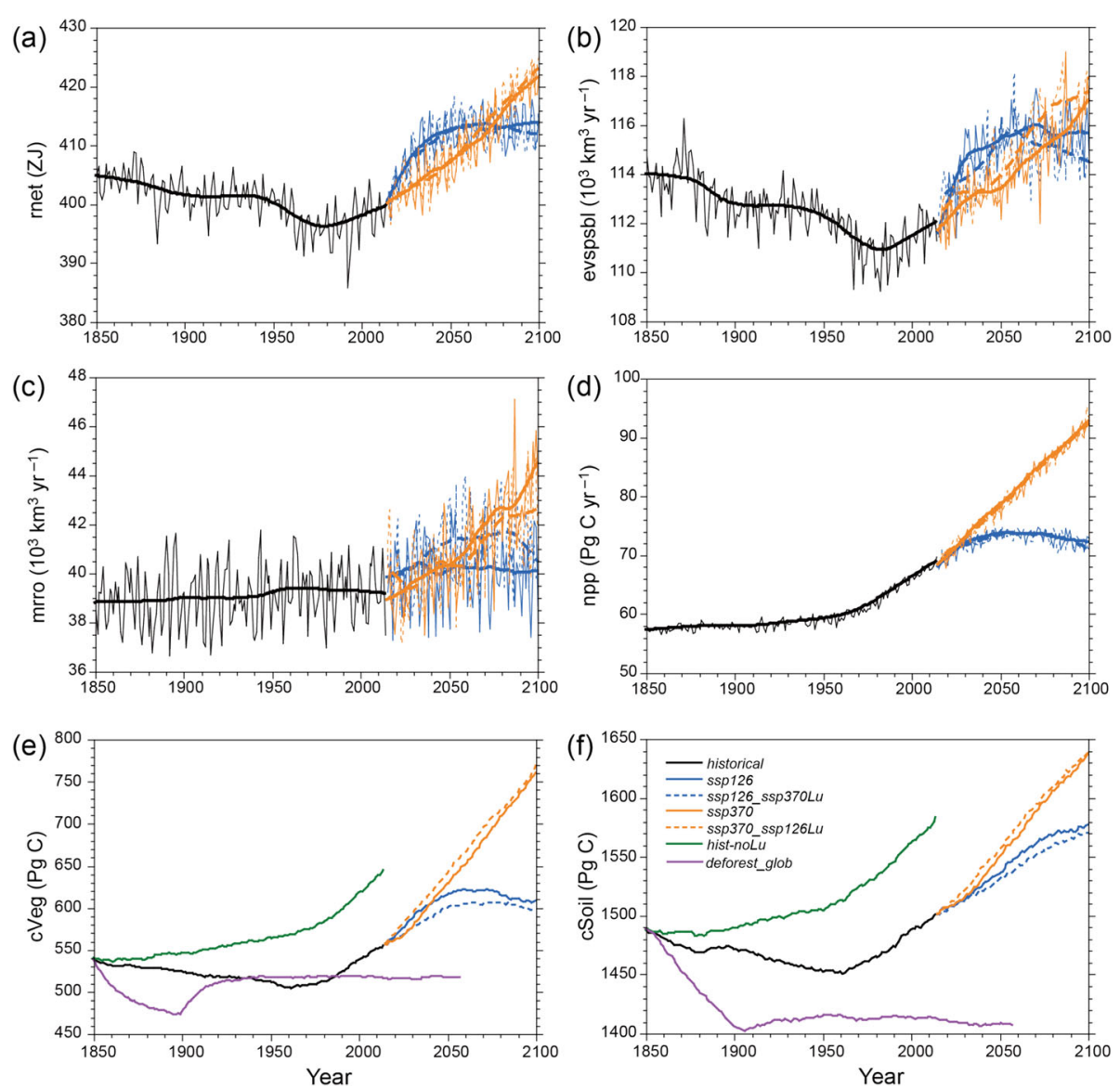

Fig. 3 Global temporal changes in a net radiation (rnet), b evapotranspiration including sublimation (evspsbl), c total runoff (mrro), d net primary production (npp), e vegetation carbon stock (cVeg), and $\mathbf{f}$ soil carbon stock (cSoil) in the CMIP6 and LUMIP experiments simulated with MIROC-ES2L

The temporal variation of rnet, that is, a decrease until the 1970s and a subsequent increase, is consistent with the global dimming and brightening revealed by observations of incoming solar radiation (Wild et al. 2005). The simulated historical trend in evspsbl (Fig. 3b) was comparable to that in rnet and caused the simulated total global evapotranspiration to decrease by $3 \times 10^{3} \mathrm{~km}^{3}$ year $^{-1}$ by ca. 1980 . The decrease in net radiation until the 1970s likely affected evspsbl, and the simulated global terrestrial precipitation also showed a weak decreasing trend during that time period (Fig. S4). Global runoff discharge (mrro; Fig. 3c), however, showed a weak increasing trend with a wide range of interannual variability. Several studies have assessed the temporal changes in evspsbl and increase in mrro during the historical period (e.g., Gedney et al. 2006; Piao et al. 2007). For example, Gedney et al. (2006) attributed the historical mrro increase, at least partly, to plant responses to elevated atmospheric $\mathrm{CO}_{2}$ concentrations. Namely, stomatal closure induced by elevated $\mathrm{CO}_{2}$ concentrations resulted in a decrease of transpiration and hence an increase of runoff discharge. In contrast, Piao et al. (2007) have emphasized the impacts of land-use change (i.e., loss of forests) on historical runoff trends.

\subsection{Biogeochemical impacts: historical}

The climatological state of biogeochemical conditions captured by MIROC-ES2L corresponded well with observations (Table 1; see Hajima et al. 2020, for benchmarking). For example, the simulated annual net primary production (npp) during 1996-2005 was 66.1 Pg C year ${ }^{-1}$, which falls within the range of previous data aggregation and model estimates (Ito 2011). Similarly, the simulated global vegetation biomass (cVeg) and soil carbon stock (cSoil) of $535 \mathrm{Pg} \mathrm{C}$ and $1186 \mathrm{Pg} \mathrm{C}$, respectively, are close to the values of a synthetic overview of the global carbon cycle (IPCC 2013) and other Earth system models (Todd-Brown et al. 2013). The simulated spatial distribution of the carbon budget was reasonable, in that tropical forests had high npp and cVeg and highlatitude ecosystems had high cSoil. 

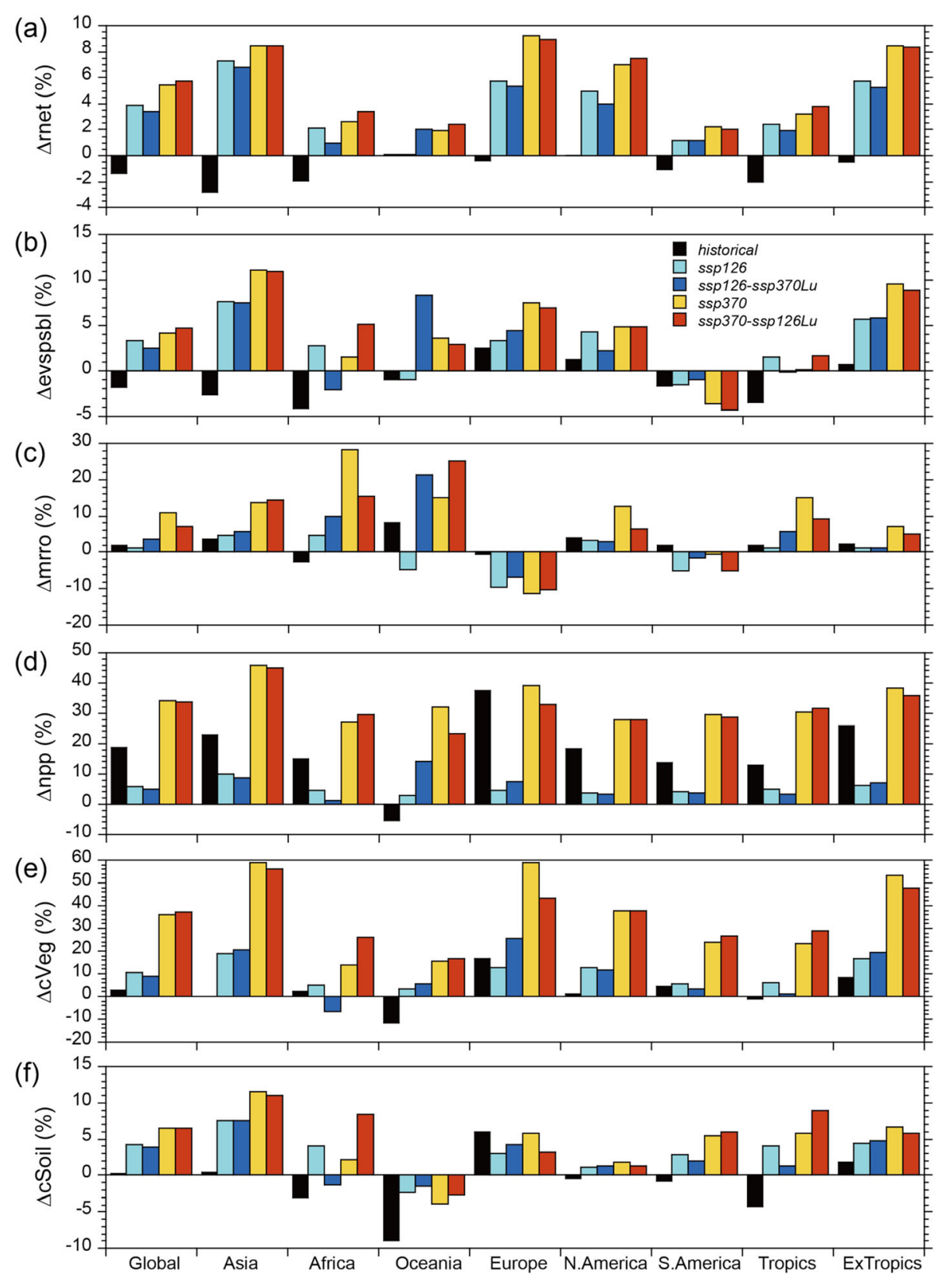

Fig. 4 Regional changes in the simulated biophysical and biogeochemical variables: a net radiation (rnet), b evapotranspiration including sublimation (evspsbl), c total runoff, $\mathbf{d}$ net primary production (npp), e vegetation carbon stock (cVeg), and $\mathbf{f}$ soil carbon stock (cSoil). Black bars show the differences between 1850-1859 and 2005-2014 in the historical period. Colored bars show the differences between 2005-2014 and 2091-2100 in the future period experiments

Land-use conversion resulted in a decline of natural vegetation, which was apparent in the historical decrease of global vegetation biomass (Fig. 3e) until 1960. Similar patterns of change in the global terrestrial carbon stock, driven mainly by deforestation, have been simulated in previous studies (e.g., McGuire et al. 2001; Devaraju et al. 2016). Land-use change, however, did not cause a decline in net primary production (Fig. 3d), because (1) croplands established at the expense of natural vegetation had comparable npp, and (2) elevated atmospheric $\mathrm{CO}_{2}$ concentration had a fertilization effect on npp. Although cropland management practices such as irrigation and fertilization were simplified in MIROCES2L, the high photosynthetic capability of crops would have enhanced land productivity. As a result of the slowdown of the natural vegetation loss after 1960 (Fig. 2), there was an acceleration of the npp increase, that led to the recovery of cVeg (Fig. 3d, e). The aboveground 
carbon budget affected the soil carbon stock (cSoil) by altering the input of litter carbon to the soil.

The simulated carbon cycle indicates that the terrestrial biosphere provided a positive biogeochemical feedback to human-induced global change until 1960 by releasing carbon stock as $\mathrm{CO}_{2}$ to the atmosphere. After 1960, the biospheric feedback became negative because carbon from the atmosphere was taken up by the terrestrial biosphere; the mean terrestrial carbon accumulation rate, $1.84 \mathrm{Pg} \mathrm{C}$ year $^{-1}$ (1.17 Pg C year ${ }^{-1}$ of cVeg and 0.67 Pg C year ${ }^{-1}$ of cSoil) was comparable to values obtained by a global carbon synthesis (Friedlingstein et al. 2019). Regionally, the responses in Oceania differed from those in other regions (Fig. 4) because cropland expansion in southern Australia, where extensive farming is conducted, negatively influenced npp and carbon stocks.

\subsection{Impacts of global deforestation on carbon stocks}

Comparison between the historical and historical_noLu experiments revealed spatiotemporal variations in the impacts of land-use change (Fig. 5). In 1870, impacts on $\mathrm{cVeg}$ and cSoil were not evident in most regions. By 1930, extensive deforestation had decreased cVeg and cSoil in eastern North America, Europe, and Southeast Asia. By 2010, a decrease in carbon pools occurred in South America and Africa as well, but cVeg had increased in Europe, and cSoil had increased in central North America, East Asia, and Europe. Cultivation with appropriate management was able to increase productivities and carbon stocks of semi-arid or infertile lands in these regions.

The idealized global deforestation experiment revealed strong impacts of land-use change on terrestrial carbon stocks (Fig. 3e, f). During the 50-year deforestation phase, vegetation biomass and soil carbon stock decreased by 64 and $81 \mathrm{Pg} \mathrm{C}$, respectively. The changes amounted to -3.2 $\operatorname{Pg~C}\left(10^{6} \mathrm{~km}^{2}\right)^{-1}$ for vegetation and - 4.1 Pg C $\left(10^{6} \mathrm{~km}^{2}\right)^{-}$ ${ }^{1}$ for soil carbon. The recovery during the restoration phase was remarkable in the vegetation carbon stock; the global total biomass recovered within 50 years to almost the initial state in 1850. In contrast, accumulation of soil carbon proceeded more slowly.

\subsection{Biogeophysical impacts: future}

Under the ssp126 and ssp370 scenarios, biogeophysical conditions simulated by MIROC-ES2L responded dramatically to the global drivers, but how they responded differed between the scenarios (Fig. 3). In the ssp126 experiment, rnet increased rapidly from 2015 to 2050 and then stabilized until the end of the twentyfirst century. In the ssp370 experiment, rnet increased gradually throughout the simulation period. These net radiation
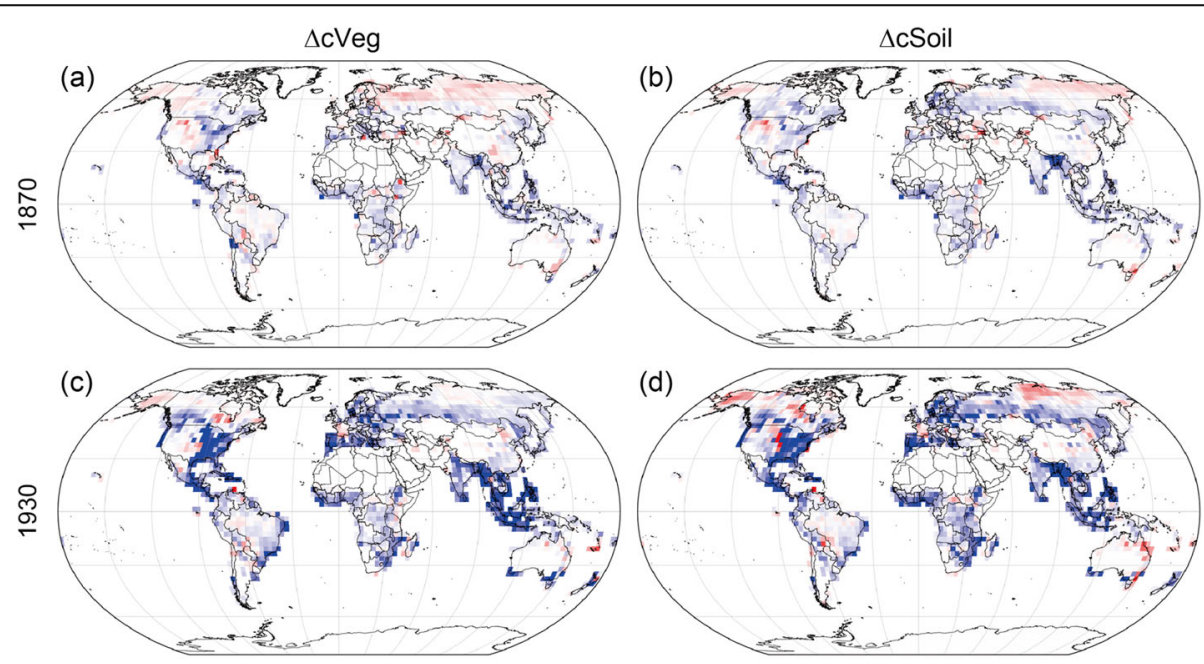

(d)
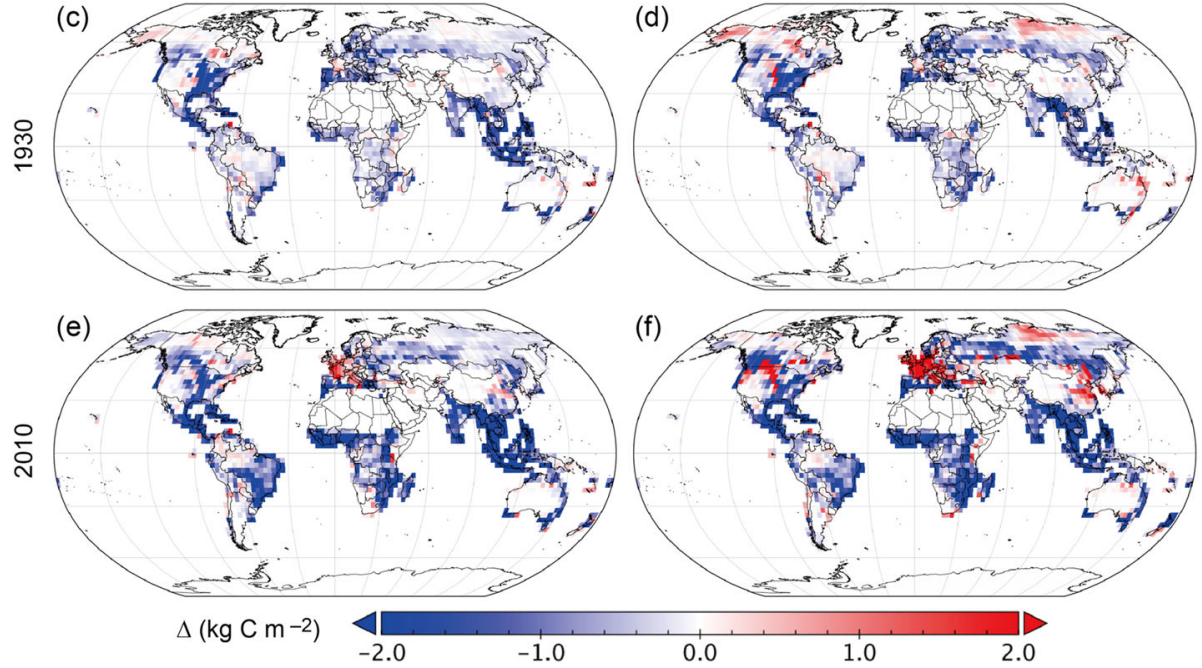

(f)

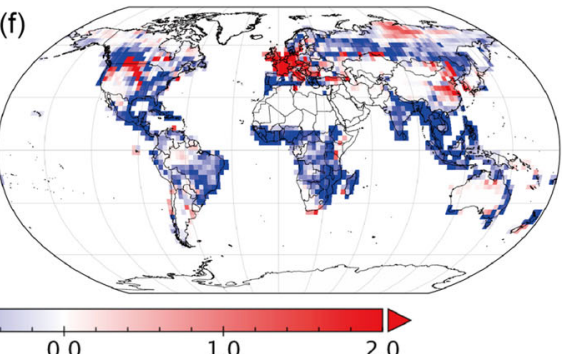

Fig. 5 Changes in carbon stocks in vegetation (cVeg: left side) and soil (cSoil: right side) between the historical and hist-noLu experiments simulated with MIROC-ES2L for a, b 1870, c, d 1930, and e, f 2010 
changes affected land evspsbl in a similar manner, because evapotranspiration is driven primarily by net radiation energy. Total runoff was simulated to increase moderately in the ssp126 experiment and markedly in the ssp370 experiment (Fig. 3c). These clear mrro responses in the future experiments contrasted with the stability of mrro in the historical experiment. The temporal responses of evapotranspiration differed between the vegetation components and the soil component (Fig. S5). In the historical period, they compensated each other, leading to relatively stable runoff discharge.

In the land-use data-exchange experiments (ssp126 ssp370Lu and ssp370_ssp126Lu), future patterns of rnet and evspsbl were largely the same as those of ssp126 and ssp370, respectively, at a global scale (Figs. 3 and 4). However, regional differences were found between the experiments with and without land-use data exchange (e.g., ssp126 and ssp126_ssp370Lu; Fig. 4). The use of the ssp370 land-use scenario resulted in lower rnet in Africa, northeastern North America, and a part of Eurasia, whereas it resulted in higher rnet in Australia and central South America. Similar differences were found in evspsbl, but only in low and middle latitudes. The changes of mrro differed from those of rnet and evspsbl; mrro increased in southern Africa, Southeast Asia, and western South America, where precipitation generally increased. Because more vegetation cover was removed in the ssp126_ssp370Lu experiment, decreases of transpiration and evaporation of canopy-intercepted water likely contributed to the increase of runoff (Fig. S5). Future temperature, precipitation, and radiation conditions did not differ greatly between the experiments with and without land-use data exchange (Fig. S4).

\subsection{Biogeochemical impacts: future}

The future response of npp (Fig. 3d) showed that it was driven primarily by atmospheric $\mathrm{CO}_{2}$ concentrations and only secondarily by climate and land use. In the ssp 126 experiment, npp increased and then reached a maximum at around 2050; in the ssp370 experiment, it increased steadily up to $90 \mathrm{Pg} \mathrm{C}$ year $^{-1}$ in 2100 . As a result of photosynthetic increase, $\mathrm{cVeg}$ and cSoil increases in both scenarios. Because carbon in soil responds to external forcing and accumulates slowly, cSoil continued to increase to the end of the twentyfirst century.

The impacts of land-use data exchange on the carbon budget were small at the global scale, especially in the case of npp; a similar weak response of npp to land use in the future has been simulated by other ESMs (e.g., Lawrence et al. 2018). The npp response was not uniform across regions; however, npp increased more in Europe, eastern North America, central Africa, and Southeast Asia in the ssp126_ssp370Lu experiment than in the ssp126 experiment. Because the ssp 370 land-use scenario indicated an extensive increase of croplands in Africa and South Asia, the npp increase was more limited by the land-use change in the ssp126_ssp370Lu experiment. Similar regional differences in the impacts of land-use data exchange were found in cVeg and cSoil.

\subsection{Changes in carbon turnover}

The mean residence time of carbon in terrestrial ecosystems is an important index of the carbon cycle and has been used to characterize the results of carbon cycle models, because it is related to the carbon accumulation potential. For example, model intercomparison studies (e.g., Friend et al. 2014) have indicated that the carbon mean residence time is a poorly constrained parameter in presently available models. Figure 6 shows the relationship between cVeg and npp (by Eq. 1, the slope, cVeg/npp, corresponds to the mean residence time) as simulated by CMIP6 models. The cVeg and npp estimates differed among the ESMs, but all of them simulated an acceleration of carbon turnover; MIROC-ES2L gave intermediate results of npp, cVeg, mean residence time, and its acceleration among the models. Similarly, Todd-Brown et al. (2013) analyzed the mean residence time of soil carbon simulated by ESMs and found that it ranges from 10.8 to 39.3 years (our estimate on the basis of the MIROC-ES2L results is 26.2 years). This remaining inter-model variability in the CMIP6 ESMs indicates a serious estimation uncertainty, which should be considered in depth in a forthcoming study.

Acceleration of carbon turnover as a result of biomass exploitation and enhanced decomposition indicates a decline of carbon storage capacity. The mean residence time of cVeg, calculated by using the definition of Erb et al. (2016), indicated such an acceleration of terrestrial carbon turnover (Fig. 7). Although the mean residence time of carbon in tropical forests was relatively long (> 15 years), it was simulated to be greatly reduced in the future. The acceleration of the carbon turnover time by a factor of $>2$ in Africa and Southeast Asia resulted in the mean residence time of carbon in these regions being halved during the simulation period. Such acceleration of the terrestrial carbon turnover is consistent with the results reported by Erb et al. (2016) for the historical period, although they also found substantial acceleration in Europe, East Asia, and eastern North America. By contrast, only our future analysis showed the clear acceleration in central and southern Africa. On the basis of their data analyses, they concluded that the mean residence time of terrestrial biomass was halved during the historical period and that $59 \%$ of the acceleration was attributable to land-use change.

\subsection{Advantages and limitations}

This study examined how well MIROC-ES2L simulated the impacts of land-use change on biogeophysical and 


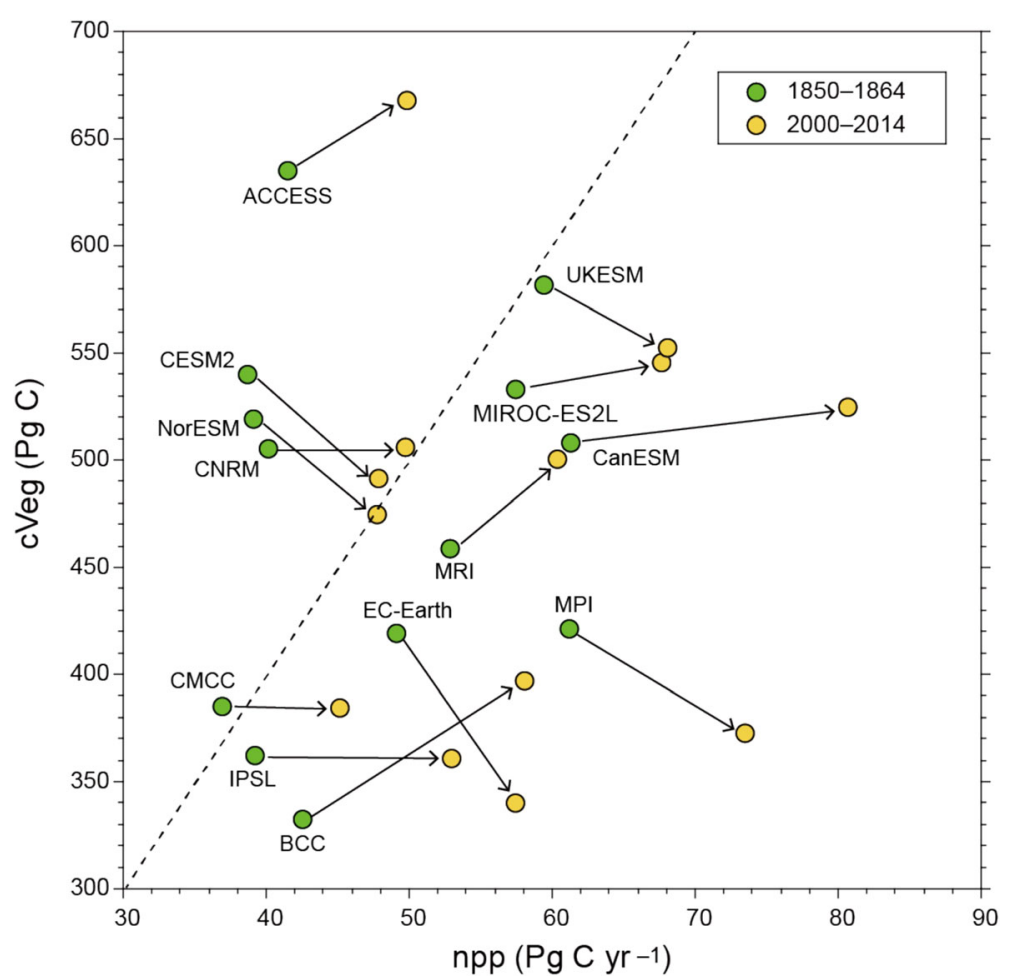

Fig. 6 Relationship between global net primary production (npp) and vegetation biomass carbon stock (cVeg) simulated by CMIP6 models. ACCE SS (ACCESS-ESM1-5), BCC (BCC-CSM2-MR), CanESM (CanESM5), CESM2, CMCC (CMCC-ESM2), CNRM (CNRM-ESM2-1), EC-Earth (EC-Earth-Veg), IPSL (IPSL-CM6A-LR), MIROC-ES2L, MPI (MPI-ESM1-2-LR), MRI (MRI-ESM2-0), NorESM (NorESM2-LM), and UKESM (UKESM1-0-LL). The dashed line shows where $\mathrm{c} V \mathrm{eg} / \mathrm{npp}=10$ (i.e., mean residence time of about 10 years). Arrows show the temporal change in each ESM; a rightward-directed arrow indicates acceleration of carbon turnover

biogeochemical conditions. By integrating physical and biological processes, the Earth system model captured the historical variations in radiation, water, and carbon budgets over the land surface. Figure 8, for example, illustrates linkages among impacts caused by land-use change, as demonstrated by the difference between the ssp126 and ssp126 ssp370Lu experiments. As shown in previous studies (e.g., Arora and Montenegro 2011), such an integration of land processes facilitates capturing the land-atmosphere interactions under shifting environmental conditions. Change in vegetation cover had sequential impacts on albedo, roughness, the radiation budget, temperature, and then evapotranspiration and runoff. This sequence of impacts was captured by the land surface scheme implemented in MIROC-ES2L, although the accuracy of the simulated impacts needs further examination. Subsequently, biogeochemical processes such as organic carbon production and decomposition were affected, directly by the loss of vegetation cover and indirectly by the change in environmental conditions. These biogeochemical impacts, which occurred at decadal time scales, were captured well by the ecosystem carbon cycle scheme implemented in the model. These results are reasons to have confidence in simulations of future land conditions by MIROC-ES2L.
However, the present study had several limitations. First, this study used the results of concentration-driven simulations, but, emission-driven simulations are required to assess biogeochemical feedback effects on the climate system of altered atmospheric $\mathrm{CO}_{2}$ concentrations. The emission-driven LUMIP experiment (esmssp585-ssp126Lu experiment; Lawrence et al. 2016), which we could not include in the present study, would be useful for this purpose. Second, because of the coarse model grid resolution (> $200 \mathrm{~km}$ ), land-use data were aggregated before use. Sub-grid land-cover heterogeneity was considered by using a simple tile-mosaic approximation (Fig. 1), but this approximation probably led to under- or over-representation of the impacts. Future improvements of high-resolution models, aided by computational advances and remote sensing data, would alleviate this problem. Third, the present ESMs, including MIROC-ES2L, do not fully account for biogeochemical feedbacks of land-use changes such as those associated with non- $\mathrm{CO}_{2}$ greenhouse gases and biogenic volatile organic compounds (Arneth et al. 2010). Landuse change should affect not only the carbon cycle but also the nitrogen cycle (e.g., accelerated mineralization and nitrous oxide emissions), but this study focused on 

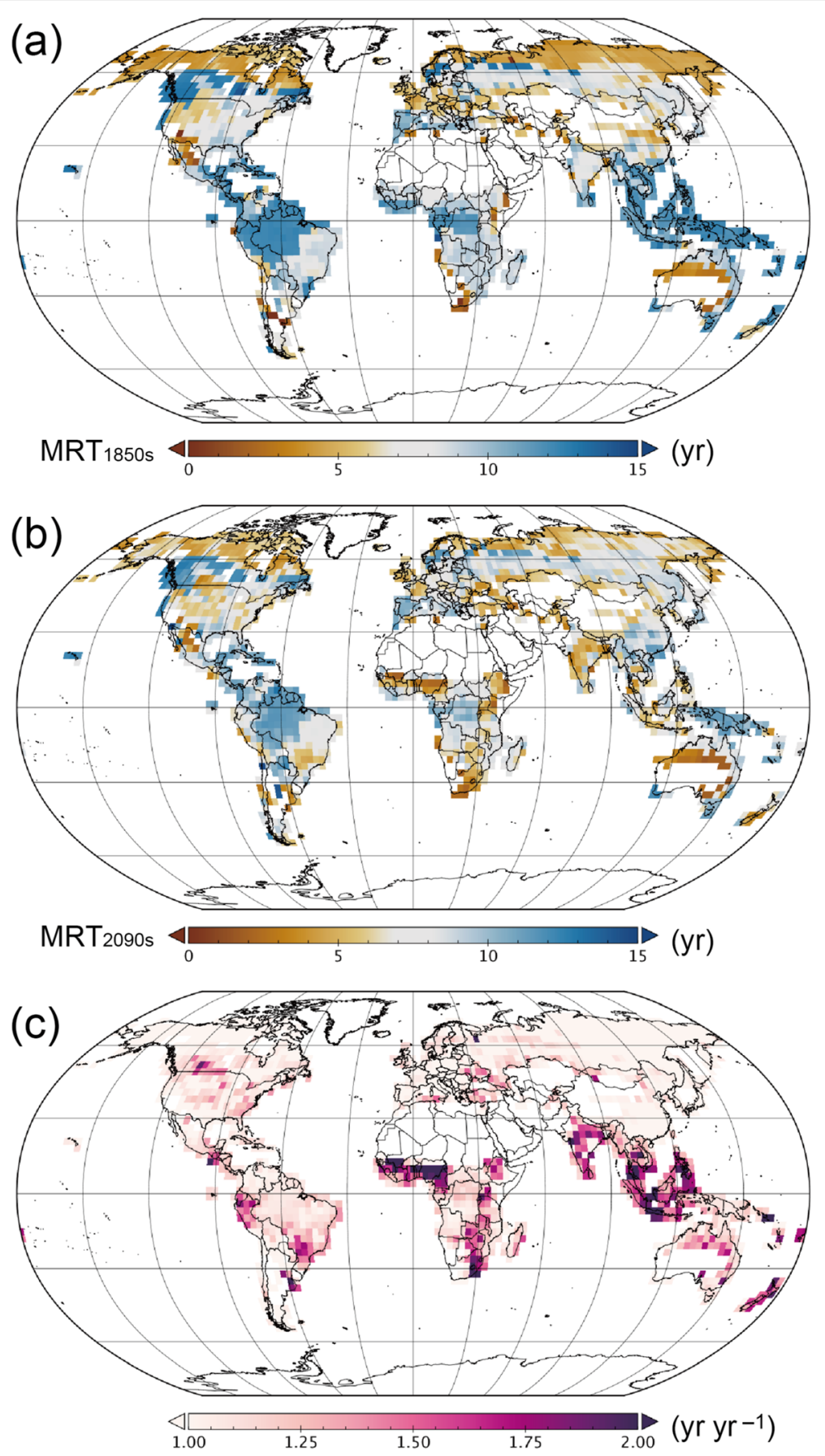

Fig. 7 Mean residence time (MRT) of vegetation biomass and its acceleration: mean residence time in the a 1850s and b 2090s in the ssp370 experiment and $\mathbf{c}$ the acceleration factor based on the definition by Erb et al. (2016)

only the carbon cycle. These limitations are unsolved problems that provide opportunities for future studies.

\section{Concluding remarks}

This study examined land-use impacts simulated by MIROC-ES2L and showed that this model gave seasonable results under different scenarios. One important implication of the study relates to the possibility of future terrestrial carbon sequestration as a means of climate change mitigation. In the present study, the ssp126 and ssp370 scenarios showed that terrestrial ecosystems might accumulate an additional 100 to $280 \mathrm{Pg}$ C globally by the end of the twentyfirst century and that this sequestration capacity is unlikely to be greatly diminished 


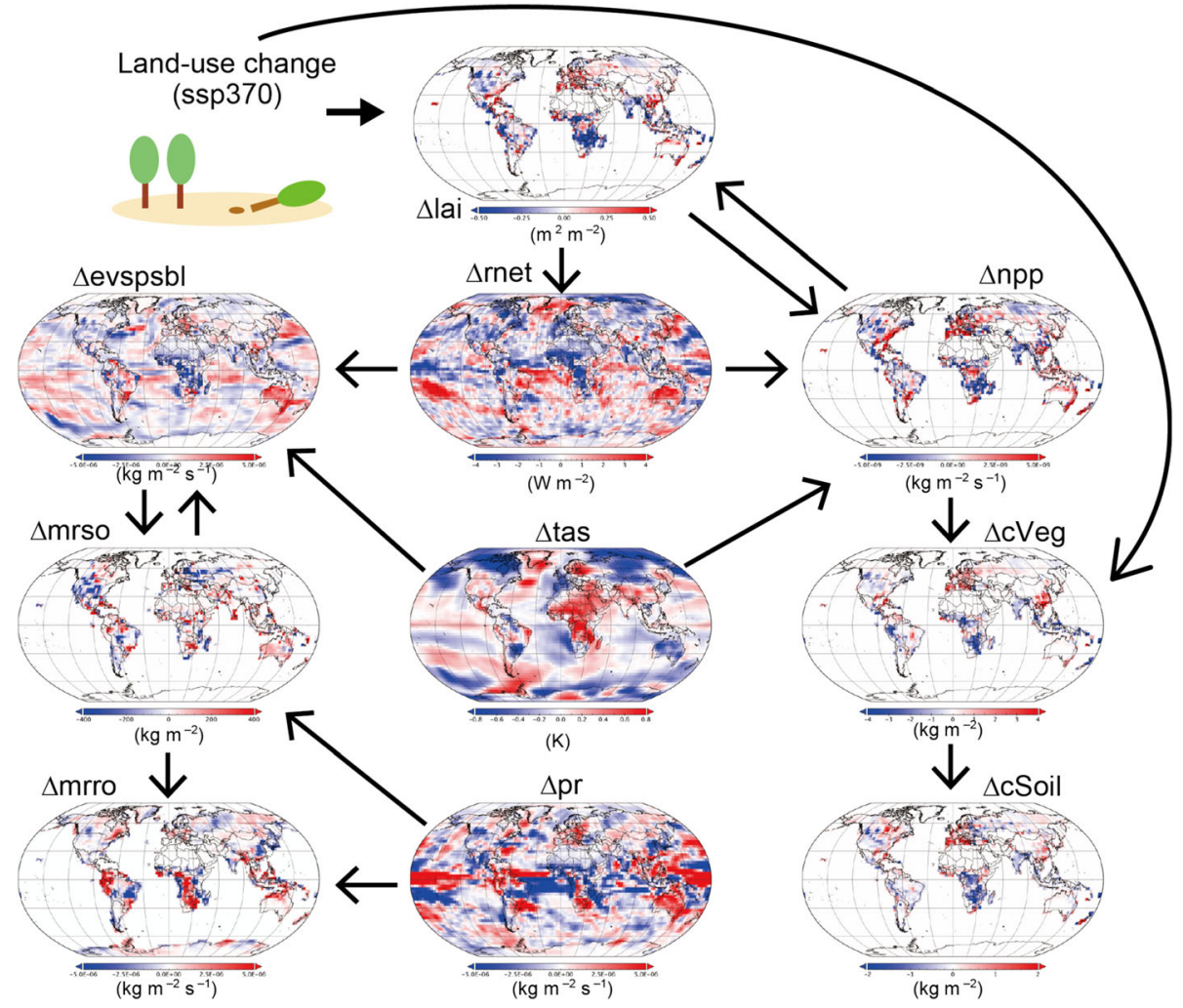

Fig. 8 Distribution of the sequential impacts of land-use change simulated with MIROC-ES2L. The maps show differences between ssp126 and ssp126-ssp370Lu during 2091-2100 (blue, lower values in ssp126-ssp370Lu; red, higher values). The arrows indicate the directions of impact

by land-use change. This persistent carbon sequestration of the future terrestrial ecosystem has important implications for climate-carbon cycle feedbacks, which play a considerable role in future climate projections.

Considering the simplicity of the land-use scenarios used in this study, more targeted land-use planning should result in additional carbon sequestration. For example, the present study did not consider soil management options such as no-tillage cultivation and bio-char amendment, for improving soil carbon capacity (Paustian et al. 2016; Soussana et al. 2019). Also, the strengthening of specific mitigation policies such as the Reduced Emission from Deforestation and forest Degradation (REDD) policy (Obersteiner et al. 2010) and forest management (e.g., Law et al. 2018) should enhance carbon sequestration in terrestrial ecosystems more than was simulated in this study. Accounting for these mitigation options, in addition to other socio-economic factors, will allow Earth system model results to be used to make more policy-relevant recommendations.

\section{Supplementary information}

Supplementary information accompanies this paper at https://doi.org/10. 1186/s40645-020-00372-w.

Additional file 1: Fig. S1. Comparison of land-use change emissions between VISIT estimation and others used in the global $\mathrm{CO}_{2}$ budget analysis (Friedlingstein et al. 2019). For keeping consistency with other model estimates, VISIT (offline version) was driven by historical climate data at spatial resolution of $0.5^{\circ} \times 0.5^{\circ}$.

Additional file 2: Fig. $\mathbf{S 2}$ Regional boundaries used in this study overlaid on the MIROC-ES2L land fraction map: Asia (856 land grids, 41.7 $\left.\times 10^{6} \mathrm{~km}^{2}\right)$, Africa (462 land grids, $\left.35.9 \times 10^{6} \mathrm{~km}^{2}\right)$, Oceania (112 land grids, $\left.7.0 \times 10^{6} \mathrm{~km}^{2}\right)$, Europe $\left(347\right.$ land grids, $\left.13.6 \times 10^{6} \mathrm{~km}^{2}\right)$, North America (653 land grids, $25.2 \times 10^{6} \mathrm{~km}^{2}$ ), and South America (271 land grids, $\left.18.7 \times 10^{6} \mathrm{~km}^{2}\right)$.

Additional file 3: Fig. S3. Changes in the cropland fraction in (a) 1861, (b) 2010, (c) 2100 by ssp126, and (d) 2100 by ssp370. Data were derived by using Land Use Harmonization version 2.

Additional file 4: Fig. S4. Temporal changes in global terrestrial-means of (a) annual near-surface air temperature, (b) mean annual precipitation, (c) downward shortwave radiation, and (d) downward longwave radiation.

Additional file 5: Fig. S5. Temporal changes in global water flows. (a) Vegetation transpiration (tran), (b) evaporation from canopy-intercepted precipitation (evspsblveg), and (c) evaporation from soil (evspsblsoi).

\section{Abbreviations}

LUMIP: Land-Use Model Intercomparison Project; MIROC-ES2L: Model for Interdisciplinary Research on Climate, Earth System version 2 for Long-term simulations

\section{Acknowledgements}

We acknowledge the World Climate Research Programme, which, through its Working Group on Coupled Modelling, coordinated and promoted CMIP6. We thank the climate modeling groups for producing and making available their model output, the Earth System Grid Federation (ESGF) for archiving 
the data and providing access, and the multiple funding agencies who supported CMIP6 and ESGF. A.I. and T.H. were supported by the Integrated Research Program for Advancing Climate Models, Ministry of Education, Culture, Sports, Science and Technology, Japan.

\section{Authors' contributions}

Al drafted the paper and TH supervised the analyses. Both authors contributed significantly to the LUMIP simulations, the interpretation of the results, and the writing of the manuscript. The author(s) read and approved the final manuscript.

\section{Funding}

A.I. and T.H. were supported by the Integrated Research Program for Advancing Climate Models (JPMXD0717935715), Ministry of Education, Culture, Sports, Science and Technology, Japan.

\section{Availability of data and materials}

The datasets supporting the conclusions of this article are available on the Earth System Grid Federation website [URL: https://esgf-node.IInl.gov/ projects/cmip6/].

\section{Competing interests}

The authors declare that they have no competing interests.

Received: 25 February 2020 Accepted: 4 September 2020 Published online: 23 September 2020

\section{References}

Adachi M, Ito A, Ishida A, Kadir WR, Ladpala P, Yamagata Y (2011) Carbon budget of tropical forests in Southeast Asia and the effects of deforestation: an approach using a process-based model and field measurements. Biogeosci 8: 2635-2647. https://doi.org/10.5194/bg-8-2635-2011

Arneth A, Harrison SP, Zaehle S, Tsigaridis K, Menon S, Bartlein PJ, Feichter J, Korhola A, Kulmala M, O'Donnell D, Schurgers G, Sorvari S, Vesala T (2010) Terrestrial biogeochemical feedbacks in the climate system. Nat Geosci 3: 525-532. https://doi.org/10.1038/ngeo905

Arneth A, Sitch S, Pongratz J, Stocker BD, Ciais P, Poulter B, Bayer AD, Bondeau A, Calle L, Chini LP, Gasser T, Fader M, Friedlingstein P, Kato E, Li W, Lindeskog M, Nabel JEMS, Pugh TAM, Robertson E, Viovy N, Yue C, Zaehle S (2017) Historical carbon dioxide emissions caused by land-use changes are possibly larger than assumed. Nat Geosci 10:79-84. https://doi.org/10.1038/NGEO2882

Arora VK, Montenegro A (2011) Small temperature benefits provided by realistic afforestation efforts. Nat Geosci 4:514-518. https://doi.org/10.1038/NGEO1182

DeFries R, Rosenzweig C (2010) Toward a whole-landscape approach for sustainable land use in the tropics. Proc Natl Acad Sci U S A 107:1962719632. https://doi.org/10.1073/pnas.1011163107

DeFries RS, Houghton RA, Hansen MC, Field CB, Skole D, Townshend J (2002) Carbon emissions from tropical deforestation and regrowth based on satellite observations for the 1980s and 1990s. Proc Natl Acad Sci U S A 99: 14256-14261

Devaraju N, Bala G, Caldeira K, Nemani R (2016) A model based investigation of the relative importance of $\mathrm{CO}_{2}$-fertilization, climate warming, nitrogen deposition and land use change on the global terrestrial carbon uptake in the historical period. Clim Dyn 47:173-190. https://doi.org/10.1007/s00382015-2830-8

Erb K-H, Fetzel T, Plutzar C, Kastner T, Lauk C, Mayer A, Niedertscheider M, Körner C, Haberl H (2016) Biomass turnover time in terrestrial ecosystems halved by land use. Nat Geosci 9:674-678. https://doi.org/10.1038/NGEO2782

Eyring V, Bony S, Meehl GA, Senior CA, Stevens B, Stouffer RJ, Taylor KE (2016) Overview of the Coupled Model Intercomparison Project Phase 6 (CMIP6) experimental design and organization. Geosci Model Dev 9:1937-1958. https://doi.org/10.5194/gmd-9-1937-2016

Foley JA, DeFries R, Asner GP, Barford C, Bonan G, Carpenter SR, Chapin FS, Coe MT, Daily GC, Gibbs HK, Helkowski JH, Holloway T, Howard EA, Kucharik CJ, Monfreda C, Patz JA, Prentice IC, Ramankutty N, Snyder PK (2005) Global consequences of land use. Science 309:570-574

Friedlingstein P, Jones MW, O'Sullivan M, Andrew RM, Hauck J, Peters GP, Peters W, Pongratz J, Sitch S, Le Quéré C, Bakker DCE, Canadell JG, Ciais P, Jackson RB, Anthoni P, Barbero L, Bastos A, Bastrikov V, Becker M, Bopp L, Buitenhuis E, Chandra N, Chevallier F, Chini LP, Currie Kl, Feely RA, Gehlen M, Gilfillan D,
Gkritzalis T, Goll DS et al (2019) Global carbon budget 2019. Earth Sys Sci Data 11:1783-1838. https://doi.org/10.5194/essd-11-1783-2019

Friend AD, Lucht W, Rademacher TT, Keribin RM, Betts R, Cadule P, Ciais P, Clark DB, Dankers R, Falloon P, Ito A, Kahana R, Kleidon A, Lomas MR, Nishina K, Ostberg S, Pavlick R, Peylin P, Schaphoff S, Vuichard N, Warszwski L, Wiltshire A, Woodward Fl (2014) Carbon residence time dominates uncertainty in terrestrial vegetation responses to future climate and atmospheric $\mathrm{CO}_{2}$. Proc Natl Acad Sci USA 111:3280-3285. https://doi.org/10.1073/pnas.1222477110

Gedney N, Cox PM, Betts RA, Boucher O, Huntingford C, Stott PA (2006) Detection of a direct carbon dioxide effect in continental river runoff records. Nature 439:835-838

Hajima T, Watanabe M, Yamamoto A, Tatebe H, Noguchi MA, Abe M, Ohgaito R, Ito AN, Yamazaki D, Okajima H, Ito A, Takata K, Ogochi K, Watanabe S, Kawamiya M (2020) Development of the MIROC-ES2L Earth system model and the evaluation of biogeochemical processes and feedbacks. Geosci Model Dev 13:2197-2244. https://doi.org/10.5194/gmd-13-2197-2020

Hansen MC, Potapov PV, Moore R, Hancher M, Turubanova SA, Tyukavina A, Thau D, Stehman SV, Goetz SJ, Loveland TR, Kommareddy A, Egorov A, Chini L, Justice CO, Townshend JRG (2013) High-resolution global maps of 21stcentury forest cover change. Science 342:850-853. https://doi.org/10.1126/ science. 1244693

Henderson-Sellers A, Dickinson RE, Durbidge TB, Kennedy PJ, McGuffie K, Pitman AJ (1993) Tropical deforestation: modeling local- to regional-scale climate change. J Geophys Res 98:7289-7315

Hibbard K, Janetos A, van Vuuren DP, Pongratz J, Rose SK, Betts R, Herold M, Feddema JJ (2010) Research priorities in land use and land-cover change for the Earth system and integrated assessment modelling. Int J Climatol 30: 2118-2128. https://doi.org/10.1002/joc.2150

Hirata R, Takagi K, Ito A, Hirano T, Saigusa N (2014) The impact of climate variation and disturbance on the carbon balance of forests in Hokkaido, Japan. Biogeosci 11:5139-5154. https://doi.org/10.5194/bg-11-5139-2014

Houghton RA (1994) The worldwide extent of land-use change. BioScience 44: 305-313

Houghton RA (2003) Revised estimates of the annual net flux of carbon to the atmosphere from changes in land use and land management 1850-2000. Tellus 55B:378-390

Hurtt GC, Chini LP, Frolking S, Betts RA, Feddema J, Fischer G, Fisk JP, Hibbard K, Houghton RA, Janetos A, Jones CD, Kindermann G, Kinoshita T, Klein Goldewijk K, Riahi K, Shevliakova E, Smith S, Stehfest E, Thomson A, Thornton $P$, van Vuuren DP, Wang YP (2011) Harmonization of land-use scenarios for the period 1500-2100: 600 years of global gridded annual land-use transitions, wood harvest, and resulting secondary lands. Clim Chang 109: 117-161. https://doi.org/10.1007/s10584-011-0153-2

Ichii K, Kondo M, Lee Y-H, Wang S-Q, Kim J, Ueyama M, Lim H-J, Shi H, Suzuki T, Ito A, Ju W, Huang M, Sasai T, Asanuma J, Han S, Hirano T, Hirata R, Kato T, Kwon H, Li S-G, Li Y-N, Maeda T, Miyata A, Matsuura Y, Murayama S, Nakai Y, Ohta T, Saitoh TM, Saigusa N, Takagi K et al (2013) Site-level model-data synthesis of terrestrial carbon fluxes in the CarboEastAsia eddy-covariance observation network: toward future modeling efforts. J For Res 18:13-20. https://doi.org/10.1007/s10310-012-0367-9

Intergovernmental Panel on Climate Change (IPCC) (2013) Climate Change 2013: the physical science basis. Cambridge University Press, p 996

Ito A (2011) A historical meta-analysis of global terrestrial net primary productivity: are estimates converging? Glob Chang Biol 17:3161-3175. https://doi.org/10.1111/j.1365-2486.2011.02450.x

Ito A (2019) Disequilibrium of terrestrial ecosystem $\mathrm{CO}_{2}$ budget caused by disturbance-induced emissions and non- $\mathrm{CO}_{2}$ carbon export flows: a global model assessment. Earth Sys Dyn 10:685-709. https://doi.org/10.5194/esd-10685-2019

Ito A, Inatomi M (2012) Water-use efficiency of the terrestrial biosphere: a model analysis on interactions between the global carbon and water cycles. J Hydrometeorol 13:681-694. https://doi.org/10.1175/JHM-D-10-05034.1

Ito A, Nishina K, Reyer CPO, François L, Henrot A-J, Munhoven G, Jacquemin I, Tian H, Yang J, Pan S, Morfopoulos C, Betts R, Hickler T, Steinkamp J, Ostberg S, Schaphoff S, Ciais P, Chang J, Rafique R, Zeng F, Zhao F (2017) Photosynthetic productivity and its efficiencies in ISIMIP2a biome models: benchmarking for impact assessment studies. Environ Res Lett 12:085001. https://doi.org/10.1088/1748-9326/aa1087a1019

Ito A, Oikawa T (2002) A simulation model of the carbon cycle in land ecosystems (Sim-CYCLE): a description based on dry-matter production theory and plot-scale validation. Ecol Model 151:147-179 
Kaplan JO, Krumhardt KM, Ellis EC, Ruddiman WF, Lemmen C, Klein Goldewijk K (2010) Holocene carbon emissions as a result of anthropogenic land cover change. Holocene 21:775-791. https://doi.org/10.1177/0959683610386983

Kato E, Kinoshita T, Ito A, Kawamiya M, Yamagata T (2013) Evaluation of spatially explicit emission scenario of land-use change and biomass burning using a process based biogeochemical model. J Land Use Sci 8:104-122. https://doi. org/10.1080/1747423X.2011.628705

Law BE, Hudiburg TW, Berner LT, Kent JJ, Buotte PC, Harmon ME (2018) Land use strategies to mitigate climate change in carbon dense temperate forests. Proc Natl Acad Sci U S A 115:3663-3668. https://doi.org/10.1073/pnas. 1720064115

Lawrence DM, Hurtt GC, Arneth A, Brovkin V, Calvin KV, Jones AD, Jones CD, Lawrence PJ, de Noblet-Ducoudré N, Pongratz J, Seneviratne SI, Shevliakova E (2016) The Land Use Model Intercomparison Project (LUMIP) contribution to CMIP6: rationale and experimental design. Geosci Model Dev 9:2973-2998. https://doi.org/10.5194/gmd-9-2973-2016

Lawrence PJ, Lawrence DM, Hurtt GC (2018) Attributing the carbon cycle impacts of CMIP5 historical and future land use and land cover change in the Community Earth System Model (CESM1). J Geophys Res Biogeosci 123: 1732-1755. https://doi.org/10.1029/2017JG004348

Malhi Y, Roberts JT, Betts RA, Killeen TJ, Li W, Nobre CA (2008) Climate change, deforestation, and the fate of the Amazon. Science 319:169-172

Marques A, Martins IS, Kastner T, Plutzar C, Theurl MC, Eisenmenger N, Huijbregts MAJ, Wood R, Stadler K, Bruckner M, Canelas J, Hilbers JP, Tukker A, Erb K, Pereira AR (2019) Increasing impacts of land use on biodiversity and carbon sequestration driven by population and economic growth. Nat Ecol Evol 3: 628-637. https://doi.org/10.1038/s41559-019-0824-3

McGuire AD, Sitch S, Clein JS, Dargaville R, Esser G, Foley J, Heimann M, Joos F, Kaplan J, Kicklighter DW, Meier RA, Melillo JM, Moore BI, Williams LJ, Wittenberg U (2001) Carbon balance of the terrestrial biosphere in the twentieth century: analysis of $\mathrm{CO}_{2}$, climate and land use effects with four process-based ecosystem models. Glob Biogeochem Cycles 15:183-206

Newbold T, Hudson LN, Arnell AP, Contu S, De Palma A, Ferrier S, Hill SLL, Hoskins AJ, Lysenko I, Phillips HRP, Burton VJ, Chng CWT, Emerson S, Gao D, Pask-Hale G, Hutton J, Jung M, Sanchez-Ortiz K, Simmonds BI, Whitmee S, Zhang H, Scharlemann JPW, Purvis A (2016) Has land use pushed terrestrial biodiversity beyond the planetary boundary? A global assessment. Science 353:288-291. https://doi.org/10.1126/science.aaf2201

Nitta T, Yoshimura K, Takata K, O'ishi R, Sueyoshi T, Kanae S, Oki T, Abe-Ouchi A, Liston GE (2014) Representing variability in subgrid snow cover and snow depth in a global land model: offline validation. J Clim 27:3318-3330

O'Neill BC, Tabaldi C, van Vuuren DP, Eyring V, Friedlingstein P, Hurtt G, Knutti R, Kriegler E, Lamarque J-F, Lowe J, Meehl GA, Moss R, Riahi K, Sanderson BM (2016) The Scenario Model Intercomparison Project (ScenarioMIP) for CMIP6. Geosci Model Dev 9:3461-3482. https://doi.org/10.5194/gmd-9-3461-2016

Obersteiner M, Huettner M, Kraxner F, McCallum I, Aoki K, Böttcher H, Fritz S, Gusti M, Havlik P, Kindermann G, Rametsteiner E, Reyers B (2010) On fair, effective and efficient REDD mechanism design. Carbon Balance Manag 4. https://doi.org/10.1186/1750-0680-4-11

Oki T, Kanae S (2006) Global hydrological cycles and world water resources. Science 313:1068-1072

Paustian K, Lehmann J, Ogle S, Reay D, Robertson GP, Smith P (2016) Climatesmart soils. Nature 532:49-57. https://doi.org/10.1038/nature17174

Piao S, Friedlingstein P, Ciais P, de Noblet-Ducoudré N, Labat D, Zaehle S (2007) Changes in climate and land use have a large direct impact than rising $\mathrm{CO}_{2}$ on global river runoff trends. Proc Natl Acad Sci U S A 104:15242-15247. https://doi.org/10.1073/pnas.0707213104

Piao S, Wang X, Park T, Chen C, Lian X, He Y, Bjerke JW, Chen A, Ciais P, Tømmervik H, Nemani RR, Myneni R (2020) Characteristics, drivers and feedbacks of global greening. Nat Rev Earth Env 1:14-27. https://doi.org/10. 1038/s43017-019-0001-x

Pongratz J, Reick CH, Houghton RA, House JI (2014) Terminology as a key uncertainty in net land use and land cover change carbon flux estimates. Earth Sys Dyn 5:177-195. https://doi.org/10.5194/esd-5-177-2014

Pongratz J, Reick CH, Raddatz T, Claussen M (2009) Effects of anthropogenic land cover change on the carbon cycle of the last millennium. Glob Biogeochem Cycles 23:GB4001. https://doi.org/10.1029/2009GB003488

Pulliainen J, Luojus K, Derksen C, Mudryk L, Lemmetyinen J, Salminen M, Ikonen J, Takala M, Cohen J, Smolander T, Norberg J (2020) Patterns and trends of Northern Hemisphere snow mass from 1980 to 2018. Nature 581:294-298. https://doi.org/10.1038/s41586-020-2258-0
Ramankutty N, Gibbs HK, Achard F, DeFries R, Foley JA, Houghton RA (2007) Challenges to estimating carbon emissions from tropical deforestation. Glob Chang Biol 13:51-66. https://doi.org/10.1111/j.1365-2486.2006.01272.x

Saatchi SS, Harris NL, Brown S, Lefsky M, Mitchard ETA, Salas W, Zutta BR, Buermann W, Lewis SL, Hagen S, Petrova S, White L, Silman M, Morel A (2011) Benchmark map of forest carbon stocks in tropical regions across three continents. Proc Natl Acad Sci U S A 108:9899-9904. https://doi.org/10. 1073/pnas.1019576108

Smith P, Davis SJ, Creutzig F, Fuss S, Minx J, Gabrielle B, Kato E, Jackson RB, Cowie A, Kriegler E, van Vuuren DP, Rogelj J, Ciais P, Milne J, Canadell JG, McCollum D, Peters G, Andrew R, Krey V, Shrestha G, Friedlingstein P, Gasser T, Grübler A, Heidug WK, Jonas M, Jones CD, Kraxner F, Littleton E, Lowe J, Moreira JR et al (2016) Biophysical and economic limits to negative $\mathrm{CO}_{2}$ emissions. Nat Clim Chang 6:42-50. https://doi.org/10.1038/NCLIMATE2870

Soussana J-F, Lutfalla S, Ehrhardt F, Roszenstock T, Lamanna C, Havlík P, Richards M, Wollenberg EL, Chotte J-L, Torquebiau E, Ciais P, Smith P, Lal R (2019) Matching policy and science: rationale for the ' 4 per 1000 - soils for food security and climate' initiative. Soil Tillage Res 188:3-15. https://doi.org/10. 1016/j.still.2017.12.002

Sud YC, Walker GK, Kim J-H, Liston GE, Sellers PJ, Lau WK-M (1996) Biogeophysical consequences of a tropical deforestation scenario: a GCM simulation study. J Clim 9:3225-3247

Takata K, Emori S, Watanabe T (2003) Development of the minimal advanced of the surface interaction and runoff. Glob Planet Chang 38:209-222

Takata K, Saito K, Yasunari T (2009) Changes in the Asian monsoon climate during 1700-1850 induced by preindustrial cultivation. Proc Natl Acad Sci U S A 106:9586-9589. https://doi.org/10.1073/pnas.0807346106

Tatebe H, Ogura T, Nitta T, Komuro Y, Ogochi K, Takemura T, Sudo K, Sekiguchi M, Abe M, Saito F, Chikira M, Watanabe S, Mori M, Hirota N, Kawatani Y, Mochizuki T, Yoshimura K, Takata K, O'ishi R, Yamazaki D, Suzuki T, Kurogi M, Kataoka T, Watanabe M, Kimoto M (2019) Description and basic evaluation of simulated mean state, internal variability, and climate sensitivity in MIROC6. Geosci Model Dev 12:2727-2765. https://doi.org/10.5194/gmd-12-2727-2019

Todd-Brown KEO, Randerson JT, Post WM, Hoffman FM, Tarnocai C, Schuur EAG, Allison SD (2013) Causes of variation in soil carbon simulations from CMIP5 Earth system models and comparison with observations. Biogeosci 10:17171736. https://doi.org/10.5194/bg-10-1717-2013

van den Hurk B, Kim H, Krinner G, Seneviratne SI, Derksen C, Oki T, Douville H, Colin J, Ducharne A, Cheruy F, Viovy N, Puma MJ, Wada Y, Li W, Jia B, Alessandri A, Lawrence DM, Weedon GP, Ellis R, Hagemann S, Mao J, Flanner MG, Zampieri M, Materia S, Law RM, Sheffield J (2016) LS3MIP (v1.0) contribution to CMIP6: the Land Surface, Snow and Soil moisture Model Intercomparison Project - aims, setup and expected outcome. Geosci Model Dev 9:2809-2832. https://doi.org/10.5194/gmd-9-2809-2016

van Vuuren DP, Riahi K, Calvin K, Dellink R, Emmerling J, Fujimori S, KC S, Kriegler E, O'Neill B (2017) The shared socio-economic pathways: trajectories for human development and global environmental change. Global Env Change 42: 148-152. doi.https://doi.org/10.1016/j.gloenvcha.2016.10.009

Wielicki BA, Barkstrom BR, Harrison EF, Lee RBI, Smith GS, Cooper JE (1996) Clouds and the Earth's Radiant Energy System (CERES): an earth observing system experiment. Bull Am Meteorol Soc 77:853-868

Wild M, Gilgen H, Roesch A, Ohmura A, Long CN, Dutton EG, Forgan B, Kallis A, Russak V, Tsvetkov A (2005) From dimming to brightening: decadal changes in solar radiation at Earth's surface. Science 308:847-850

Woodwell GM, Hobbie JE, Houghton RA, Melillo JM, Moore B, Peterson BJ, Shaver GR (1983) Global deforestation: contribution to atmospheric carbon dioxide. Science 222:1081-1086

\section{Publisher's Note}

Springer Nature remains neutral with regard to jurisdictional claims in published maps and institutional affiliations. 